\title{
Association between Periodontal Disease and Osteoporosis among Post-Menopausal Women
}

\author{
Prathibha Anand Nayak ${ }^{1 *}$, Ullal Anand Nayak ${ }^{2}$ and R. Mythili ${ }^{3}$ \\ 'Associate Professor, Periodontics, Department of Oral Basic and Clinical Sciences, Ibn Sina National \\ College for Medical Studies, Jeddah - 22421, Saudi Arabia; drprathibha_an@yahoo.co.in \\ ${ }^{2}$ Associate Professor, Pediatric Dentistry, Department of Preventive Dental Sciences, Ibn Sina National \\ College for Medical Studies, Jeddah - 22421, Saudi Arabia; dranandnayak@yahoo.co.in \\ ${ }^{3}$ Former Dean, Professor and Head, Department of Periodontics, Rajah Muthiah Dental College \\ Hospital, Annamalai University, Annamalai Nagar, C. Kothangudi - 608002, Tamil Nadu; \\ India; mythswam@gmail.com
}

\begin{abstract}
Aims: The present study was conducted to evaluate the relationship between systemic bone mineral density and periodontal status in postmenopausal women, and to evaluate the association between serum estrogen levels and periodontal status in osteoporotic post-menopausal women. Methodology: 200 postmenopausal women were subjected to systemic bone density measurements using the Achilles Express Densitometer, out of which 136 were enrolled for the study. Based on the systemic bone mineral density values obtained, the patients were divided into osteoporosis, osteopenia and non-osteoporosis groups. Plaque index, probing pocket depth, clinical attachment loss and tooth loss were recorded. Those patients who had bone mineral density values corresponding to the osteoporosis group were subjected to blood investigations to determine the serum estrogen, calcium, phosphorus and alkaline phosphatase levels. Results: Of the 136 women, 42 were in the osteoporosis group (30.9\%), 66 were in the osteopenia group (48.5\%) and 28 were in the nonosteoporosis group (20.5\%). Age of the postmenopausal women, their plaque score, tooth loss, clinical attachment loss and probing pocket depth had a direct and significant association with osteoporosis. The osteopenia group was not statistically significant when compared to non-osteoporosis group with respect to the selected variables. No statistical significance between serum estrogen levels and any of the selected variables in the osteoporosis group was observed. Conclusion: The study confirms a significant direct association between osteoporosis and periodontitis among post-menopausal women.
\end{abstract}

Keywords: Bone Mineral Density, Osteoporosis, Periodontal Disease, Post-Menopausal Women

\section{Introduction}

Periodontal disease that is initiated by microbial pathogens leads to periodontal tissue destruction, including breakdown of alveolar bone ${ }^{1}$. The host's immunoinflammatory response to the periodontal pathogens is responsible for most of the periodontal destruction. There are also a number of environmental and acquired factors that modify a patient's risk of developing periodontal disease.
Osteoporosis is a condition or a disease that makes the bones more porous and fragile, thereby increasing the risk of fracture. Sometimes even a minor bump during the course of normal daily activities can cause fracture. Both periodontal disease and osteoporosis are defined by predominant bone resorptive activity and their progression/severity may be assessed systemically and/or locally ${ }^{2}$. Although a causal relationship is unclear, there are numerous shared risk factors between osteoporosis

${ }^{*}$ Author for correspondence 
and periodontitis. These established and shared potential risk factors not only provide information regarding their etiologies but also can assist the clinicians in preventing or managing both diseases simultaneously ${ }^{3}$.

Approximately, 200 million people have been affected by osteoporosis making it a serious health problem ${ }^{4}$. Out of these, about $40 \%$ of women and $20 \%$ of men are likely to have a fragility (osteoporotic) fracture during their lifetime. 15 to $30 \%$ mortality may be attributed to osteoporotic fractures ${ }^{5}$. Race, gender and ethnicity are factors that influence the prevalence of osteoporosis and the incidence of fracture. Age-related decrease in bone mineral density starts during midlife both for men and women. But women in their early years of menopause experience rapid bone loss, placing them at earlier risk for fractures ${ }^{6}$. There are certain predictors of low bone mass which include female gender, increased age, race (white), low Body Mass Index (BMI) and weight, history of osteoporosis among family members, positive history of fracture and smoking. However, consumption of alcohol and beverages with caffeine has shown inconsistent association with reduced bone mass ${ }^{7}$.

Decline in estrogen levels during and after menopause is the most common cause of osteoporosis in women. Estrogen deficiency affects systemic bone resorption and formation, and locally can affect the stability of alveolar bone structure in postmenopausal women ${ }^{8}$. It has been suggested that estrogen can prevent alveolar bone resorption thus influencing tooth retention ${ }^{9}$.

About $70 \%$ to $80 \%$ of bone strength is determined by bone mineral density and is considered as the single best predictor of osteoporosis-related fractures ${ }^{10}$. Several equipment have been developed and utilized to detect low Bone Mineral Density (BMD) and to identify individuals at high risk of osteoporotic fractures, which include single or dual photon absorptiometry, Quantitative Computed Tomography (QCT), single or Dual X-Ray Absorptiometry (DXA) and Quantitative Ultra-Sound (QUS) $)^{11,12}$.

Prospective studies conducted in humans support an association of osteoporosis with the onset and progression of periodontal disease ${ }^{13}$. Both periodontitis and osteoporosis present bone loss as common hallmark. Systemic bone loss imposes risk for periodontal disease and there is increasing evidence that suggests loss of bone mass characteristic of osteoporosis is associated with periodontal disease and tooth loss.
Hence the present study was attempted with the following aims and objectives.

1. To evaluate the association between systemic bone mineral density and periodontal status in postmenopausal osteoporotic, osteopenia and nonosteoporotic women.

2. To evaluate the association between systemic bone mineral density, periodontal status and serum estrogen levels in osteoporotic postmenopausal women.

\section{Materials and Methods}

The present study was conducted in the Department of Periodontics, Rajah Muthiah Dental College and Hospital, Annamalai University, India. A convenient sample of 200 postmenopausal women aged between 45 and 70 years were selected who were attending the regular OPD of the department. Women who had their last menstrual period followed by amenorrhea lasting for 1 year were considered as post-menopausal in the present study ${ }^{14}$.

Prior consent of all the patients was obtained for the screening and the investigations required and the approval was also obtained by the University's ethical committee. All the patients were subjected to a detailed case history taking with respect to the medical status, postmenopausal status, history of fracture or fall and family history of fracture or osteoporosis. The dental history of tooth loss and oral prophylaxis were recorded. The age, height and body weight of the patients were also noted. An intra-oral examination was carried out on the dental chair under adequate light to assess the periodontal parameters by a qualified examiner. Plaque index (Sillness and Loe), probing pocket depth, clinical attachment loss and tooth loss were recorded.

All the postmenopausal women were subjected to systemic BMD measurements using the Achilles Express Ultrasonometer (Densitometer). It is an FDA approved densitometer used to determine the systemic bone mineral density manufactured by General Electric (Medical Instrument Company) USA and marketed by Wipro GE Medical Systems based in Bangalore. High frequency sound waves (ultrasound) are used to evaluate bone status in the heel (the Os calcis). The Achilles Express measurements were performed by a qualified technician with the patient seated, with one foot placed on the Achilles Express foot positioner. The heel of the subject was surrounded by inflated membranes containing 
warm water as this facilitates ultrasound transmission. A transducer that was present on one side of the heel helps in converting an electrical signal into a sound wave, which is made to pass through the water and the heel of the patient. A transducer placed on the opposite side of the heel at a fixed distance received the sound wave and converted it to an electrical signal which was analyzed by the Achilles Express program ${ }^{15}$.

The Achilles Express Ultrasonometer measures speed of sound and the frequency dependent attenuation of the sound waves and combines them to form a clinical measure termed Stiffness Index which are expressed as T-scores and help in the diagnosis of osteoporosis.

Based on the WHO T-Score criteria for bone mineral density ${ }^{16}$, the patients were divided into the following groups. Group 1- Osteoporosis (BMD<-2.5) Group 2Osteopenia (BMD -1 to -2.5); Group 3- Non-osteoporosis $(\mathrm{BMD}>-1)$

The criteria for diagnosis of osteoporosis was made based on clinical evidence and systemic bone mineral density values. The inclusion criteria for the osteoporotic group were: 1. signs and symptoms of osteoporosis, which included back pain, history of fracture, loss of height and altered posture due to spinal deformity; 2 . systemic bone mineral density values as determined by using a portable peripheral bone densitometer; and 3. presence of at least 7 natural teeth.

The exclusion criteria included: 1. patient suffering from any other bone disease like osteomalacia, hyperparathyroidism, multiple myeloma as determined by biochemical analysis (Serum calcium, phosphorus, alkaline phosphatase); 2. patients on hormone replacement therapy or Bis-phosphonates as therapy for osteoporosis.

The osteopenia group included those postmenopausal women who were diagnosed as osteopenia based on the systemic bone mineral density values.

The non-osteoporotic group included postmenopausal women among whom osteoporosis was excluded based on bone mineral density values, orthopedic consultation and the following exclusion criteria: 1. early or surgical menopause; 2. family history of osteoporosis; 3. complaints of back pain, loss of height and history of fracture; 4. excessive caffeine consumption, smoking, alcohol; 5. prolonged immobility; 6. inadequate dietary sources of calcium; significant drug history (steroids, heparin and diuretics), and 7. significant medical history (renal and hepatic disease, diabetes).
Those patients of the osteoporosis group were further subjected to blood investigations to estimate the serum estrogen (estradiol II), calcium, phosphorus and alkaline phosphatase levels. Based on the history and intraoral examination, utilizing the inclusion and exclusion criteria, out of the 200 patients who were screened for osteoporosis, 136 patients were enrolled for the study. The edentulous patients were excluded from the study.

All the above obtained data were subjected to statistical analysis for comparison between the groups. One-way ANOVA test was used to compare the mean variables (age, body weight, plaque score, tooth loss, probing pocket depth and clinical attachment loss) in the three groups. Further, Scheffe's multiple comparison tests were performed to evaluate their inter-group significance. The correlation coefficients of selected variables were obtained by Pearson's correlation significance test. Student's $t$ test was done to reveal the statistical significance of serum estrogen levels in the osteoporosis group. The results were then tabulated.

\section{Results}

Of the 136 women, 42 were in the osteoporosis group (30.9\%), 66 were in the osteopenia group (48.5\%) and 28 were in the non-osteoporosis group (20.5\%).

Table 1 shows the mean and standard deviation of age, plaque score, and body weight of the subjects by groups. One-way ANOVA test showed that the body weight among women in all the groups did not differ statistically. However, there were significant differences with respect to age and plaque score when compared between the three groups. Scheffe's multiple comparison test indicated that osteoporosis group was associated with significantly higher age and plaque scores than the other two groups $[p<0.001]$. The osteopenia group revealed no statistically significant difference when compared to nonosteoporosis group with respect to these three variables.

Table 2 shows the mean and standard deviation of serum estrogen levels in the osteoporosis group and the BMD levels. Out of 42 subjects in the osteoporosis group, 24 had BMD levels between -2.5 to -3 with the mean serum estrogen levels of $13.45 \mathrm{Pg} / \mathrm{m}$ with the standard deviation of 12.31 and 18 had BMD levels $<-3$ with the mean serum estrogen levels of $9.34 \mathrm{Pg} / \mathrm{m}$. Since serum estrogen levels were determined only in the osteoporosis group, student's $\mathrm{t}$ test was done which revealed no statistical significance. 
Table 1. Intergroup comparison of age, plaque score and body weight

\begin{tabular}{|c|c|c|c|c|c|c|}
\hline \multicolumn{7}{|c|}{ Age } \\
\hline \multirow[b]{2}{*}{ Group } & \multirow[b]{2}{*}{$\mathbf{N}$} & \multicolumn{2}{|c|}{ Age in years } & \multirow[b]{2}{*}{$\mathbf{F}$} & \multirow[b]{2}{*}{ Significance } & \multirow[b]{2}{*}{ Scheffe's Multiple comparison } \\
\hline & & Mean & Std. Deviation & & & \\
\hline Osteoporosis & 42 & 60.71 & 6.87 & 9.86 & $<0.001$ & \multirow{4}{*}{$\begin{array}{c}\text { Osteoporosis vs. Osteopenia, Non- } \\
\text { osteoporosis }\end{array}$} \\
\hline Osteopenia & 66 & 56.68 & 6.57 & & & \\
\hline Non-osteoporosis & 28 & 54.14 & 4.68 & & & \\
\hline Total & 136 & 57.40 & 6.74 & & & \\
\hline \multicolumn{7}{|c|}{ Plaque Score } \\
\hline \multirow{2}{*}{ Group } & \multirow{2}{*}{$\mathbf{N}$} & \multicolumn{2}{|c|}{ Plaque score } & \multirow{2}{*}{$\mathbf{F}$} & \multirow{2}{*}{ Significance } & \multirow{2}{*}{ Scheffe's Multiple comparison } \\
\hline & & Mean & Std. Deviation & & & \\
\hline Osteoporosis & 42 & 1.63 & 0.36 & 11.08 & $<0.001$ & \multirow{3}{*}{$\begin{array}{c}\text { Osteoporosis vs Osteopenia, Non- } \\
\text { osteoporosis }\end{array}$} \\
\hline Osteopenia & 66 & 1.41 & 0.35 & & & \\
\hline Non-osteoporosis & 28 & 1.22 & 0.37 & & & \\
\hline \multicolumn{7}{|c|}{ Body Weight } \\
\hline \multirow{2}{*}{ Group } & \multirow{2}{*}{$\mathbf{N}$} & \multicolumn{2}{|c|}{ Body Weight (Kg) } & \multirow{2}{*}{$\mathbf{F}$} & \multirow{2}{*}{ Significance } & \multirow{2}{*}{ Scheffe's Multiple comparison } \\
\hline & & Mean & Std. Deviation & & & \\
\hline Osteoporosis & 42 & 56.19 & 11.93 & & 0.112 & - \\
\hline Osteopenia & 66 & 59.77 & 10.78 & & & \\
\hline Nonosteoporosis & 28 & 62.17 & 14.92 & & & \\
\hline Total & 136 & 59.16 & 12.19 & & & \\
\hline
\end{tabular}

Mean difference is significant at 0.05 level.

Table 2. Mean and standard deviation of serum estrogen levels in the osteoporosis group

\begin{tabular}{|c|c|c|c|c|c|}
\hline \multirow{2}{*}{ BMD level } & \multirow{2}{*}{$\mathbf{N}$} & \multicolumn{2}{|c|}{ Serum Estrogen Pg/m } & \multirow{2}{*}{ Student's test value } & Significance \\
\cline { 3 - 4 } & & Mean & Std. Deviation & \multirow{2}{*}{2.109} & 0.154 \\
\hline-2.5 to -3 & 24 & 13.45 & 12.31 & \\
\hline$<-3$ & 18 & 9.34 & 4.20 & \\
\hline
\end{tabular}

Mean difference is significant at 0.05 level.

However, it can be observed that as the BMD levels decrease, serum estrogen levels also decrease.

Table 3 shows the mean and standard deviation of clinical attachment levels, probing pocket depth and tooth loss among the subjects by groups. One-way ANOVA test indicated that mean clinical attachment loss, probing pocket depth and tooth loss were significantly different between the three groups. Further, Scheffe's multiple comparison test indicated that osteoporosis group had significantly higher clinical attachment loss, probing pocket depth and tooth loss than the other two groups [ $\mathrm{p}<0.001]$. The osteopenia group did not show any statistically significant difference when compared to nonosteoporosis group.

Table 4 shows the correlation coefficient between serum estrogen levels and other selected variables in osteoporosis group. No statistical significance between serum estrogen levels and any of the selected variables was observed.

Table 5 shows the correlation coefficients between the selected variables. There was a high negative relationship between BMD and postmenopausal status, CAL and 
Table 3. Intergroup comparison of Clinical Attachment Level (CAL), probing pocket depth and tooth loss

\begin{tabular}{|c|c|c|c|c|c|c|}
\hline \multicolumn{7}{|c|}{ Clinical Attachment Level (mm) } \\
\hline \multirow{2}{*}{ Group } & \multirow{2}{*}{$\mathbf{N}$} & \multicolumn{2}{|c|}{ Clinical Attachment Level } & \multirow{2}{*}{$\mathbf{F}$} & \multirow{2}{*}{ Significance } & \multirow{2}{*}{$\begin{array}{l}\text { Scheffe's Multiple } \\
\text { comparison }\end{array}$} \\
\hline & & Mean & Std. Deviation & & & \\
\hline Osteoporosis & 42 & 6.05 & 1.17 & \multirow{4}{*}{34.06} & \multirow{4}{*}{$<0.001$} & \multirow{4}{*}{$\begin{array}{l}\text { Osteoporosis vs } \\
\text { Osteopenia, Non- } \\
\text { osteoporosis }\end{array}$} \\
\hline Osteopenia & 66 & 4.94 & 0.62 & & & \\
\hline Non-osteoporosis & 28 & 4.59 & 0.48 & & & \\
\hline Total & 136 & 5.21 & 0.99 & & & \\
\hline \multicolumn{7}{|c|}{ Probing Pocket Depth (mm) } \\
\hline \multirow{2}{*}{ Group } & \multirow{2}{*}{$\mathbf{N}$} & \multicolumn{2}{|c|}{ Probing Pocket Depth } & \multirow{2}{*}{$\mathbf{F}$} & \multirow{2}{*}{ Significance } & \multirow{2}{*}{$\begin{array}{l}\text { Scheffe's Multiple } \\
\text { comparison }\end{array}$} \\
\hline & & Mean & Std. Deviation & & & \\
\hline Osteoporosis & 42 & 5.00 & 26.08 & \multirow{4}{*}{26.08} & \multirow{4}{*}{$<0.001$} & \multirow{4}{*}{$\begin{array}{l}\text { Osteoporosis vs } \\
\text { Osteopenia, Non- } \\
\text { osteoporosis }\end{array}$} \\
\hline Osteopenia & 66 & 4.29 & 0.58 & & & \\
\hline Non-osteoporosis & 28 & 4.10 & 0.36 & & & \\
\hline Total & 136 & 4.47 & 0.67 & & & \\
\hline \multicolumn{7}{|c|}{ Tooth Loss ( number of teeth) } \\
\hline \multirow{2}{*}{ Group } & \multirow{2}{*}{$\mathbf{N}$} & \multicolumn{2}{|c|}{ Tooth Loss } & \multirow{2}{*}{$\mathbf{F}$} & \multirow{2}{*}{ Significance } & \multirow{2}{*}{$\begin{array}{l}\text { Scheffe's Multiple } \\
\text { comparison }\end{array}$} \\
\hline & & Mean & Std. Deviation & & & \\
\hline Osteoporosis & 42 & 17.00 & 7.04 & \multirow{4}{*}{45.66} & \multirow{4}{*}{$<0.001$} & \multirow{4}{*}{$\begin{array}{l}\text { Osteoporosis vs } \\
\text { Osteopenia, Non- } \\
\text { osteoporosis }\end{array}$} \\
\hline Osteopenia & 66 & 8.51 & 4.47 & & & \\
\hline Non-osteoporosis & 28 & 6.50 & 3.14 & & & \\
\hline Total & 136 & 10.72 & 6.71 & & & \\
\hline
\end{tabular}

Mean difference is significant at 0.05 levels.

Table 4. Correlation coefficient between serum estrogen levels and other selected variables in osteoporosis group

\begin{tabular}{|c|c|c|c|c|c|c|}
\hline \multicolumn{2}{|c|}{} & $\begin{array}{c}\text { Bone Mineral } \\
\text { Density }\end{array}$ & PM Status & Weight & $\begin{array}{c}\text { Probing Pocket } \\
\text { Depth }\end{array}$ & Clinical Attachment Level \\
\hline $\begin{array}{c}\text { Serum } \\
\text { Estrogen } \\
\text { Level } \\
(\mathrm{N}=42)\end{array}$ & $\begin{array}{c}\text { Pearson } \\
\text { Correlation }\end{array}$ & .126 & -.113 & -.003 & -.078 & .086 \\
\cline { 2 - 7 } & Sig (2-tailed) & .426 & .477 & .987 & .625 & .590 \\
\hline
\end{tabular}

${ }^{\star \star}$ Correlation is significant at the 0.01 level (2-tailed), ${ }^{\star}$ Correlation is significant at the 0.05 level (2-tailed). 
Table 5. Correlation coefficients of selected variables

\begin{tabular}{|c|c|c|c|c|}
\hline & Post menopausal status & Body weight & Clinical attachment loss & Probing pocket depth \\
\hline Bone & $-.328^{* *}$ & $.210^{*}$ & $-.480^{* *}$ & $-.432^{* *}$ \\
Mineral & .000 & .014 & .000 & .000 \\
Density & 136 & 136 & 136 & 136 \\
\hline Post & & $-.271^{* *}$ & $.432^{* *}$ & $.377^{* *}$ \\
Menopausal & & .001 & .000 & .000 \\
Status & & 136 & 136 & 136 \\
\hline Body & & & -.157 & -.148 \\
Weight & & & .068 & .084 \\
& & & 136 & 136 \\
\hline Clinical & & & & $.744^{* *}$ \\
Attachment & & & & .000 \\
Loss & & & & 136 \\
\hline
\end{tabular}

Pearson Correlations Significance (2 tailed)

${ }^{\star}$ Correlation is significant at the 0.05 level (2-tailed), ${ }^{*}$ Correlation is significant at the 0.01 level (2-tailed).

probing pocket depth. BMD and body weight were positively related. There was a negative relationship between postmenopausal status and body weight, whereas postmenopausal status and CAL, probing pocket depth were positively related. Body weight was found to have a negative relationship with CAL, probing pocket depth. CAL was positively related with probing pocket depth.

\section{Discussion}

Possibility that osteoporosis and periodontal diseases may be related should be considered because of the common etiological agents that they share, which could affect or modulate their natural history ${ }^{15}$. Periodontitis has long been identified as an infectious disease causing destruction of the alveolar bone and periodontal soft tissues and accounts for majority of tooth loss among adults. Recent literature supports their association in humans ${ }^{17}$. Studies have highlighted that low bone mass could be independently associated with loss of tooth and alveolar bone height. But, there are less consistent studies that focus on the relation between clinical attachment loss and osteoporosis.

Systemic BMD measurements for the postmenopausal women were performed using the Achilles Express Ultrasonometer. QUS can assess both bone mass and architecture and is used for evaluating fracture risk. The ultrasound densitometry of the Os calsis is highly reproducible and has a high correlation with BMD measured by DXA in different parts of the skeleton such as the spine or femur ${ }^{15}$. In direct comparisons, heel ultrasonography was slightly worse than but comparable to DXA of the hip in women older than 65 years of age ${ }^{18}$. QUS generally uses calcaneal site for BMD measurements as it has a high metabolic activity and demineralization pattern similar to that of spine. The QUS measures parameters such as broadband ultrasound attenuation and speed of sound from which stiffness index can be calculated $^{19}$. QUS is transportable, cost effective, time saving, radiation free and is a useful means for early diagnosis of and prescreening for osteoporosis compared to DXA, which is non-transportable and emits low doses of ionizing radiation. QUS of the calcaneus has been used in previous studies as a prescreening tool to identify patients at high risk, for whom treatment need to be initiated, and also to identify patients at low risk thus limiting the need for a DXA measurement ${ }^{20}$. In the present study, Ultrasonometer was chosen to measure BMD of Os calsis as it was feasible and economical, portable, radiation free and gave fairly consistent readings.

The optimal time intervals for screening for osteoporosis are not yet established. The average yearly rate of bone loss is less than $1 \%$ (range $0.5 \%$ to $2 \%$ ) in postmenopausal women. The United States Preventive Services Task Force hence recommends routine BMD screening for all women who are 65 years and above. Depending on the individual's current BMD and risk factors for osteoporosis, follow-up screening intervals of 2 to 5 years may be considered ${ }^{21}$. 
Estrogen levels are higher in women and plays important role in body functions, such as the menstrual cycle. Estradiol, estriol, and estrone are the three forms of estrogen. Out of the three forms of estrogen, estradiol is the most potent form, with highest affinity for cell receptors ${ }^{22}$. Estrogen acts on bone cells and influences immune system through oxidative stress, thus regulating bone metabolism. Therefore, estrogen is considered a major systemic regulator of bone tissue metabolism ${ }^{23}$. Estrogen takes the help of Estrogen Receptors (ER): ER $\alpha$ and ER $\beta$ to perform all of the mechanisms in the bone tissue $^{24}$. ER $\alpha$ is the primary estrogen receptor found in female skeleton and promotes stimulatory effects on bone mass ${ }^{25}$. Estrogen deficiency increases the life of osteoclasts and decreases the life of osteoblasts ${ }^{26}$. Estrogen loss leads to elevated bone resorption which is caused by an increase in the amount of cytokines that regulate osteoclast generation, such as: RANK-ligand; prostaglandin E2, interleukin-1, 2 and 6, tumor necrosis factor-a; and macrophage-colony stimulating factor. Normally, estrogen suppresses the production of all of these cytokines directly or indirectly ${ }^{27}$. Payne, et al. $(1997)^{28}$ suggested estrogen sufficiency as serum E2 levels between 40 and $400 \mathrm{pg} / \mathrm{ml}$, whereas estrogen deficiency to be serum E2 level below $30 \mathrm{pg} / \mathrm{ml}$. In the present study, although the serum estrogen levels were not statistically significant with bone mineral density levels, all the patients except one had serum E2 levels less than 30pg/ $\mathrm{ml}$. The student's $\mathrm{t}$ test revealed no statistical significance between serum estrogen levels and bone mineral density values. This was because serum estrogen levels were determined only in the osteoporosis group; however, it was observed that as the BMD levels decreased, serum estrogen levels also decreased. However, it is not certain that estrogen deficiency is entirely responsible for the decrease in bone mass after the loss of or decrease in ovarian function. Clearly, progesterone deficiency could also be a factor. Estrogen probably functions by attenuating bone resorption and progesterone increasing bone formation ${ }^{28}$.

In the present study, the age of the postmenopausal women was highly associated with the bone mineral density levels. As the age and postmenopausal years increased, the BMD level decreased. This could suggest that either the reduced BMD level may be due to estrogen deficiency or age related changes. These findings are in accordance with the studies done by $\mathrm{Du}$, et al. $(2015)^{29}$ who reported that the greatest amount of postmenopausal bone loss occurred within seven years of reaching menopause.

The present study indicated that osteoporosis group had significantly higher plaque scores than the other two groups. In contrast to these findings, Von, et al. (1994) showed that osteoporotic women had significantly lower mandibular BMD values than controls without any significant differences with respect to plaque scores. Also, women with osteoporotic fractures had greater attachment loss than women without fractures.

In a recent study, the age, CAL, PPD and plaque index has been found to have positive association with weak correlation whereas gingival index has shown a negative association with weak correlation with the osteoporosis ${ }^{31}$. In the present study, osteoporosis group had significantly higher clinical attachment loss and probing pocket depth than the other two groups. Pilgram, et al. (1999) ${ }^{32}$ attributed the changes in the alveolar bone height and clinical attachment levels to systemic changes in bone health rather than to periodontal disease. However, the weak correlations between changes in attachment level and bone height are similar to recent studies of periodontal disease.

Resorption of the alveolar bone may have influenced clinical periodontal parameters, such as tooth loss, Probing Depth (PD), or Clinical Attachment Loss (CAL) ${ }^{33}$. Elders, et al. $(1992)^{34}$ showed a significant negative correlation whereas of mean alveolar bone density to tooth loss and mean probing depth in dentulous subjects. However, association between systemic osteoporosis and tooth loss may be a more sensitive indicator as compared to clinical measures, such as PD and CAL since the values of $\mathrm{PD}$ and CAL depend on the number of retained teeth ${ }^{35}$. Since premature tooth loss is more common among osteoporotic subjects, the clinical parameters are limited in sensitivity for typical cross-sectional studies. On the other hand, tooth loss presents a cumulative result of progressing periodontal pockets and attachment loss. Klemetti, et al. $(1994)^{36}$ reported that out of 227 post-menopausal women, about $50 \%$ had teeth only in the mandibular arch, a jaw with a higher BMD. This could be the reason why the study failed to find a positive association between osteoporosis and the Community Periodontal Index of Treatment Needs (CPITN).

The women in the osteoporotic group exhibited significantly higher tooth loss in the present study. Certain studies suggested that osteoporosis could influence the rate of bone loss in chronic periodontitis patients 
which further explains the greater number of edentulous subjects found in these studies ${ }^{37}$.

Yoshihara, et al. $(2005)^{38}$ found a weak but statistically significant relationship between BMD and periodontal disease progression, and in a later study found a correlation between BMD of the Os calcis and the number of retained teeth. Osteoporotic women have been found to have a higher risk for tooth loss, followed by greater bone resorption after tooth loss, when compared with healthy women of the same age range ${ }^{39}$.

While determining tooth loss, role of other clinical and socioeconomic factors need to be considered that can affect the prevalence of periodontal disease; thereby influencing the tooth loss results. In a study when patient age and periodontal status were included, tooth loss was not significantly different between subjects with low and high spinal bone density ${ }^{40}$.

To date, most of the studies in this area have been conducted with limitations such as small sample sizes, lack of elimination of confounding factors and varied definitions for the disease/conditions. Host factors such as genetic susceptibility, low bone density, alveolar bone loss due to periodontal inflammation, and shared exposure to certain risk factors may directly or indirectly influence the periodontal disease onset and progression. Diminished systemic loss of bone density seen in osteoporosis can also affect the oral cavity, providing a host system that is increasingly susceptible to infectious periodontal tissue destruction. Both diseases can cause community-health concerns and their prevalence has been shown to increase with age.

As health care providers, dentists will contribute to their patients' health if they make the following recommendations to postmenopausal women:

1. Emphasis on proper daily oral hygiene practice and frequent dental appointments to remove plaque and calculus deposits.

2. Recommending calcium supplements.

3. Instructing the patients to abstain from smoking and from excessive caffeine and alcohol consumption.

4. Referring postmenopausal women with oral manifestations of osteoporosis to their physicians for medical evaluation and treatment.

\section{Conclusion}

The present study has confirmed the direct significant association between osteoporosis versus age, plaque score, tooth loss clinical attachment loss and probing pocket depth of the postmenopausal women. No statistical significance between serum estrogen levels and any of the selected variables in the osteoporosis group was observed. To better evaluate the relationship between bone mineral density and periodontal disease, additional prospective longitudinal studies with further analysis of possible confounding factors for osteoporosis and periodontal disease in larger cohorts of post-menopausal women are needed. However, it must be borne in mind that the primary etiology of periodontal disease is pathogenic bacterial plaque in a susceptible patient. Therefore, if good oral hygiene is combined with regular check-ups, the effects that any of osteoporotic factors may exert on the periodontal tissues can be minimized.

\section{References}

1. Krall EA, Wehler C, Garcia RI, Harris SS, Dawson-Hughes B. Calcium and vitamin D supplements reduce tooth loss in the elderly. Am. J. Med. 2001; 111(6):452-56. https://doi. org/10.1016/S0002-9343(01)00899-3.

2. Gomes-Filho IS, Passos JD, Cruz SS, Vianna MI, Cerqueira ED, Oliveira DC, et al. The association between postmenopausal osteoporosis and periodontal disease. J. Periodontol. 2007; 78(9):1731-40. https://doi.org/10.1902/ jop.2007.070057. PMid: 17760543.

3. Wang CW, McCauley LK. Osteoporosis and periodontitis. Curr. Osteoporos. Rep. 2016; 14(6):284-91. https://doi. org/10.1007/s11914-016-0330-3. PMid: 27696284, PMCid: PMC5654540.

4. Aaseth J, Boivin G, Andersen O. Osteoporosis and trace elements-an overview. J. Trace. Elem. Med. Biol. 2012; 26(23):149-52. https://doi.org/10.1016/j.jtemb.2012.03.017. PMid: 22575536.

5. Cummings SR, Melton LJ. Epidemiology and outcomes of osteoporotic fractures. Lancet. 2002; 359(9319):1761-67. https://doi.org/10.1016/S0140-6736(02)08657-9.

6. Black DM, Rosen CJ. Postmenopausal osteoporosis. N. Engl. J. Med. 2016; 374(3):254-62. https://doi.org/10.1056/ NEJMcp1513724. PMid: 26789873.

7. NIH consensus development panel on osteoporosis prevention, diagnosis, and therapy. Osteoporosis prevention, diagnosis, and therapy. J. Am. Med. Assoc. 2001; 285(6):78595. https://doi.org/10.1001/jama.285.6.785. PMid: 11176917. 
8. Norderyd OM, Grossi SG, Machtei EE. Periodontal status of women taking postmenopausal estrogen supplementation. J. Periodontol. 1993; 64(10):957-62. https://doi.org/10.1902/ jop.1993.64.10.957. PMid: 8277404.

9. Levin VA, Jiang X, Kagan R. Estrogen therapy for osteoporosis in the modern era. Osteoporos. Int. 2018; 29(5):1049-55. https://doi.org/10.1007/s00198-018-4414-z. PMid: 29520604.

10. Brown JP, Josse RG, Scientific Advisory Council of the Osteoporosis Society of Canada. 2002 clinical practice guidelines for the diagnosis and management of osteoporosis in Canada. Can. Med. Assoc. J. 2002; 167(10 suppl):S1-34.

11. Shibu B, Singh AJ, Khanna T, Singh AB. Normative broadband ultrasound attenuation and speed of sound data and correlation between $\mathrm{t}$-scores of quantitative ultrasound and dual energy $\mathrm{x}$-ray absorptiometry among females of Manipur. Int. J. Med. Res. Health Sci. 2018; 7(6):100-04.

12. Roldan EQ, Brianese N, Raffetti E, Focà E, Pezzoli MC, Bonito A, et al. Comparison between the gold standard DXA with calcaneal Quantitative Ultrasound basedStrategy (QUS) to detect osteoporosis in an HIV infected cohort. Braz. J. Infect. Dis. 2017; 21(6):581-86. https://doi. org/10.1016/j.bjid.2017.08.003. PMid: 28950107.

13. Maria S, Witt-Enderby PA. Melatonin effects on bone: Potential use for the prevention and treatment for osteopenia, osteoporosis, and periodontal disease and for use in bone-grafting procedures. J. Pineal. Res. 2014; 56(2):115-25. https://doi.org/10.1111/jpi.12116. PMid: 24372640.

14. Soules MR, Sherman S, Parrott E, Rebar R, Santoro N, Utian W, et al. Executive summary: Stages of Reproductive Aging Workshop (STRAW). Fertil. Steril. 2001; 76:874-78. https://doi.org/10.1016/S0015-0282(01)02909-0.

15. Yoshihara A, Seida Y, Hanada N, Miyazaki H. A longitudinal study of the relationship between periodontal disease and bone mineral density in community-dwelling older adults. J. Clin. Periodontol. 2004; 31(8):680-84. https://doi. org/10.1111/j.1600-051X.2004.00548.x. PMid: 15257747.

16. Anonymous WHO Study Group. Assessment of fracture risk and its application to screening for post-menopausal osteoporosis. WHO, Geneva; 1994.

17. Nicolatou-Galitis O, Schiødt M, Mendes RA, Ripamonti C, Hope S, Drudge-Coates L, et al. Medication-related osteonecrosis of the jaw: Definition and best practice for prevention, diagnosis, and treatment. Oral Surg., Oral Med., Oral Pathol., Oral Radiol. 2019; 127(2):117-35. https://doi. org/10.1016/j.oooo.2018.09.008. PMid: 30393090.

18. Xu Y, Guo B, Gong J, Xu H, Bai Z. The correlation between calcaneus stiffness index calculated by QUS and total body BMD assessed by DXA in Chinese children and adolescents. J. Bone Miner Metab. 2014; 32(2):159-66. https://doi. org/10.1007/s00774-013-0474-5. PMid: 23695447.
19. Guglielmi G, de Terlizzi F. Quantitative ultrasound in the assessment of osteoporosis. European J. Radiol. 2009; 71(3):425-31. https://doi.org/10.1016/j.ejrad.2008.04.060. PMid: 19651483.

20. Vallipakorn SA, Vallipakorn O, Sophonsritsuk A, Jirapinyo M, Sritara C. The optimal cut-points for weight and nonweight quantitative ultrasound of the calcaneus to screen osteoporosis in postmenopausal women. J. Med. Assoc. Thai. 2016; 99(3):249-56.

21. Curry SJ, Krist AH, Owens DK, Barry MJ, Caughey AB, Davidson KW, et al. Screening for osteoporosis to prevent fractures: US preventive services task force recommendation statement. J. Am. Med. Assoc. 2018; 319(24):2521-31. https:// doi.org/10.1001/jama.2018.7498. PMid: 29946735.

22. Novack DV. Estrogen and bone: osteoclasts take center stage. Cell Metab. 2007; 6(4):254-56. https://doi.org/10.1016/j. cmet.2007.09.007. PMid: 17908554.

23. Khosla S, Oursler MJ, Monroe DG. Estrogen and the skeleton. Trends Endocrinol. Metab. 2012; 23(11):576-81. https://doi.org/10.1016/j.tem.2012.03.008. PMid: 22595550, PMCid: PMC3424385.

24. Jeyakumar M, Carlson KE, Gunther JR, Katzenellenbogen JA. Exploration of dimensions of estrogen potency parsing ligand binding and coactivator binding affinities. J. Biol. Chem. 2011; 286(15):12971-82. https://doi.org/10.1074/ jbc.M110.205112. PMid: 21321128, PMCid: PMC3075970.

25. Ohlsson C, Vandenput L. The role of estrogens for male bone health. Eur. J. Endocrinol. 2009; 160(6):883-89. https://doi.org/10.1530/EJE-09-0118. PMid: 19304870.

26. Lane NE. Epidemiology, etiology, and diagnosis of osteoporosis. Am. J. obstet. Gynecol. 2006; 194(2):S3-11. https://doi.org/10.1016/j.ajog.2005.08.047. PMid: 16448873.

27. Nair SP, Wilson M, Reddi K, White P, Henderson B. Bacterially induce bone destruction: Mechanisms and misconceptions. Infect Immun. 1996; 64(7):2371-80. https://doi.org/10.1128/IAI.64.7.2371-2380.1996. PMid: 8698454, PMCid: PMC174085.

28. Payne JB, Zachs NR, Reinhardt RA, Nummikoski PV, Patil $\mathrm{K}$. The association between estrogen status and alveolar bone density changes in postmenopausal women with a history of periodontitis. J. Periodontol. 1997; 68(1):24-31. https://doi.org/10.1902/jop.1997.68.1.24. PMid: 9029448.

29. Du Z, Steck R, Doan N, Woodruff MA, Ivanovski S, Xiao Y. Estrogen deficiency-associated bone loss in the maxilla: A methodology to quantify the changes in the maxillary intra-radicular alveolar bone in an ovariectomized rat osteoporosis model. Tissue Engineering Part C: Methods. 2015; 21(5):458-66. https://doi.org/10.1089/ten. tec.2014.0268. PMid: 25315176.

30. Von Wowern N, Klausen B, Kollerup G. Osteoporosis: A risk factor in periodontal disease. J. Periodontol. 1994; 
65(12):1134-38. https://doi.org/10.1902/jop.1994.65.12.1134. PMid: 7877085.

31. Manjunath SH, Rakhewar P, Nahar P, Tambe V, Gabhane M, Kharde A. Evaluation of the prevalence and severity of periodontal diseases between osteoporotic and nonosteoporotic subjects: A cross-sectional comparative study. J. Contemp. Dent. Pract. 2019; 20(10):12-23. https:// doi.org/10.5005/jp-journals-10024-2717. PMid: 31883261.

32. Pilgram TK, Hildebolt CF, Yokoyama-Crothers N, Dotson M, Cohen SC, Hauser JF, et al. Relationships between longitudinal changes in radiographic alveolar bone height and probing depth measurements: Data from postmenopausal women. J. Periodontol 1999; 70(8):82933. https://doi.org/10.1902/jop.1999.70.8.829. PMid: 10476888 .

33. Weyant RJ, Pearlstein ME, Churak AP, Forrest K, Famili $\mathrm{P}$, Cauley JA. The association between osteopenia and periodontal attachment loss in older women. J. Periodontol. 1999; 70(9):982-91. https://doi.org/10.1902/jop.1999.70.9.982. PMid: 10505800.

34. Elders PJ, Habets LL, Netelenbos JC, van der Linden LW, van der Stelt PF. The relation between periodontitis and systemic bone mass in women between 46 and 55 years of age. J. Clin. Periodontol. 1992; 19(7):492-96. https://doi. org/10.1111/j.1600-051X.1992.tb01162.x. PMid: 1430285.
35. Martinez-Maestre MA, Gonzalez-Cejudo C, Machuca G, Torrejon R, Castelo-Branco C. Periodontitis and osteoporosis: A systematic review. Climacteric. 2010; 13(6):523-29. https:// doi.org/10.3109/13697137.2010.500749. PMid: 20690866.

36. Klemetti E, Collin HL, Forss H, Markkanen H, Lassila V. Mineral status of skeleton and advanced periodontal disease. J. Clin. Periodontol. 1994; 21(3):184-88. https://doi. org/10.1111/j.1600-051X.1994.tb00301.x. PMid: 8157771.

37. Taguchi A, Tanimoto K, Suei Y, Otani K, Wada T. Oral signs as indicators of possible osteoporosis in elderly women. Oral Surg., Oral Med., Oral Pathol., Oral Radiol., Endodontol. 1995; 80(5):612-16. https://doi.org/10.1016/ S1079-2104(05)80158-1.

38. Yoshihara A, Seida Y, Hanada N, Nakashima K, Miyazaki $\mathrm{H}$. The relationship between bone mineral density and the number of remaining teeth in community-dwelling older adults. J. Oral Rehabil. 2005; 32(10):735-40. https://doi. org/10.1111/j.1365-2842.2005.01491.x. PMid: 16159351.

39. Bodic F, Hamel L, Lerouxel E, Baslé MF, Chappard D. Bone loss and teeth. Joint Bone Spine. 2005; 72(3):215-21. https:// doi.org/10.1016/j.jbspin.2004.03.007. PMid: 15850992.

40. Mohammad AR, Bauer RL, Yeh CK. Spinal bone density and tooth loss in a cohort of postmenopausal women. Int. J. Prosthodont. 1997; 10(4):381-85. 